УДК 37

DOI $10.31483 / \mathrm{r}-32859$

С.П. Руссков

ПЕДАГОГИЧЕСКОЕ СОПРОВОЖДЕНИЕ ФОРМАЛИЗОВАННОЙ СИСТЕМЫ МОНИТОРИНГА РЕЗУЛЬТАТОВ РЕАЛИЗАЦИИ ФЕДЕРАЛЬНОГО ГОСУДАРСТВЕННОГО ОБРАЗОВАТЕЛЬНОГО СТАНДАРТА В ОБРАЗОВАТЕЛЬНОЙ ОРГАНИЗАЦИИ

Аннотация: в статье рассматривается актуальная проблема современной системы образования - необходимость педагогического сопровождения формализованной системы мониторинга реализациии требований ФГОС в образовательных учреждениях с иелью прослеживания и выявления результатов педагогической деятельности. Автор анализирует икольную систему оченки качества образования, определяет возможные формы и виды формализации результатов требований ФГОС в образовательной организацчии. $B$ статье имеются предложения по использованию разных способов и каналов получения информаџии для проведения оченивания и диагностики качества образования.

Ключевые слова: педагогическое, сопровождение, формализация, мониторинг, качество образования, видь мониторинга, внутриикольный мониторинг.

\title{
S.P. Russkov
}

\section{PEDAGOGICAL MAINTENANCE OF ALGORITHMIC SYSTEM OF FEDERAL STATE EDUCATIONAL STANDARD RESULTS'MONITORING IN EDUCATIONAL ESTABLISHMENT}

Abstract: this article looks through the current problem of the modern educational system - the need of pedagogical maintenance of algorithmic system of monitoring of FSES requirements in educational establishment in order to deduce and fetch out the results of pedagogical activity. The author analyses the system of quality evaluation of education, used in schools, points the possible forms and types of formalisation of FSES requirements' results in educational establishment. The article also suggests to use 
different ways to get the information for the purpose of evaluation and diagnostics of the quality of education.

Keywords: pedagogical maintenance, formalization, monitoring, quality of education, types of monitoring, intraschool monitoring.

Когда в своей лексике мы применяем понятия «педагогическая», «педагогическое» мы подчеркиваем, что какой-нибудь вопрос или явление относится или рассматривается с точки зрения педагогической науки. А педагогическая наука, как известно, занимается выявлением сущности педагогических явлений их закономерностей, и перспектив развития системы образования как одного из факторов развития человека, а в целом и социума на многие годы. В этом случае уникальность образования выражается в том, что - это единственный институт государства, через который проходят и развиваются все люди социума, обеспечивая себя определенным уровнем образования.

С другой стороны, педагогика как наука и искусство, выявляя педагогические закономерности, разрабатывает на их основе технологии педагогической деятельности, вооружая ими педагогических работников инновационными путями решения актуальных проблем воспитания и обучения.

Таким образом, из сказанного следует, что педагогика сопровождает как развитие системы образования, так и сам процесс образования. Когда мы говорим о педагогическом сопровождении какого-либо социального или образовательного процесса, то имеем в виду активную разработку педагогикой цели и задач, моделей решения выявленных проблем современного образования на основе применения научных методов обнаружения противоречий и проблем, существующих в образовательной системе.

Сегодня в системе образования идет процесс комплексной, всесторонней реализации Федеральных государственных образовательных стандартов (далее - ФГОС) с целью обновления всех звеньев образовательной системы и всех сфер образовательной деятельности в соответствии с требованиями современной жизни. При этом реализация требований стандартов предусматривает со- 
хранение и приумножение лучших традиций отечественного образования научности, духовности и нравственности, культурологичности и т. д. В то же время стандарты предусматривают осуществление мониторинга деятельности образовательных организаций по реализации требований ФГОС. В этом случае педагогическая наука для осуществления научного подхода к мониторингу процесса и результатов деятельности образовательных организаций по реализации требований ФГОС определяет необходимость педагогического сопровождения формализованной системы мониторинга реализации ФГОС. Педагогическое сопровождение системы мониторинга в образовательных организациях необходимо с целью прослеживания результатов процесса реализации ФГОС:

- эффективности реализации цели и задач, эффективного функционирования образовательной системы образования в новых условиях деятельности, сохранения положительного опыта унаследованных от прошлого;

- предусмотренных стандартом изменений в содержании образования, технологии и организации самой образовательной деятельности;

- изменений в образовательном мировоззрении работников образования, обучающихся и родителей;

- доступности, качества и эффективности образования и др.

Следовательно, мониторинг, прежде всего - это прослеживание результатов деятельности образовательной организации от определения цели и задач внедрения ФГОС, а затем и процесса реализации ФГОС. Сущность и функции мониторинга предполагают систематический сбор и обработку, анализ результатов введения ФГОС в образовательной организации, которые необходимы для определения точки отсчета деятельности образовательной организации. Ведь чтобы определить уровень развития чего-либо, необходимо сначала определить точку отсчета, то есть начальный уровень показателей деятельности образовательной организации, отсюда и начинается мониторинг образовательной деятельности организации.

Таким образом, мониторинг выполняет разные функции, в том числе, важнейшую - организационную: 
-выявляет начальное состояние готовности образовательной системы к изменению педагогического процесса в условиях реализации ФГОС;

-определяет изменения образовательной среды, в которой будет осуществляться обновление содержания образования и его результатов;

-выявляет необходимость коррекции тех или иных действий образовательной организации по внедрению и реализации ФГОС.

С целью успешной организации мониторинга педагогическая наука рекомендует создать школьную систему оценки качества образования. Эта структурная организация образовательной системы призвана направить свою деятельность на получение объективных результатов мониторинга реализации требований ФГОС на основе применения рекомендованных стандартом комплекса критериев, процедур и технологий оценки и его использование как инструментария управления качеством образования.

Для получения объективной информации процесса отслеживания результатов реализации ФГОС педагогическая теория рекомендует применение формализованной системы мониторинга, то есть отображение результатов прослеживания с помощью общепринятых форм - научного языка (слово, образ, схема, таблица, цифры и т. д.).

В современном понимании «формализация» (от лат. forma - вид, образ) это отображение полученной информации с помощью символов какого-либо языка (слово, выражение, цифры, графически знаки, символы и.т. д.). Формализовать - это значит представить (представлять) содержательную сторону исследуемого явления в виде формальной системы, например, термина, формулы или цифр в таблице. В науке принято выделять две формы формализации - естественную и научную. Нас в данном случае интересует научная форма формализации.

В процессе научной формализации, с опорой на закономерности и принципы педагогики, осуществляется точное и объективное отображение конкретных действий и отношений субъектов образовательной системы, характеризующих результаты реализации требований ФГОС. Но здесь необходимо сказать, что не 
всегда в ходе формализации полученной информации они могут адекватно отразить результаты реализации требований ФГОС. Например, символы не могут точно отобразить слово или термин, в содержательном или количественном плане.

В таком случае в педагогической науке принято применять другой вид формализации - дедуктивную, или логическую формализацию. Такая формализация представляет собой отображение всеобщих взаимосвязей между знаниями: понятиями, суждениями, умозаключениями, содержательными теориями, системами теорий - с помощью дедуктивно упорядоченных систем символов.

Из вышеизложенного следует, что формализовать систему мониторинга реализации ФГОС в образовательной организации - это значит представить содержательную сторону процесса реализации ФГОС в виде формализованной системы или исчисления, то есть в виде определенного алгоритма, таблиц, схем, графиков, гистограмм, языком цифр и т. д.

Итак, педагогическое сопровождение формализованной системы мониторинга итогов реализации ФГОС в образовательной организации строится на основе прослеживания результатов деятельности коллектива образовательной организации с учётом основных циклов функционирования образовательной организации (учебная четверть, полугодие, учебный год), жизненных циклов образовательных концепций и программ; основных этапов школьного образования (начальная, основная, средняя школа).

Технология осуществления формализованного мониторингового исследования включает в себя наиболее целесообразные способы и приемы каналов получения информации для проведения оценивания и диагностики качества образования. Сюда необходимо включить: анализ статистических данных; анкетирование; экспертное оценивание; контентный анализ документов; количественные оценки методики и процедуры; заключения, решения и оценки официальных структур разных уровней.

Мониторинг результатов реализации ФГОС включает в себя: мониторинг результатов учебной деятельности и мониторинг результатов воспитательной 
деятельности образовательной организации. Формализованная система мониторинга позволяет выделить уровни и виды мониторинга (таблица 1).

Таблица 1

Уровни и виды мониторинга

\begin{tabular}{|c|c|c|}
\hline $\begin{array}{l}\text { № } \\
\Pi / \Pi\end{array}$ & Типология видов мониторинга & Содержание \\
\hline 1. & По масштабу целей образования & Стратегический, тактический, оперативный \\
\hline 2. & По этапам обучения & $\begin{array}{c}\text { Входной или отборочный, учебный или про- } \\
\text { межуточный, входной или итоговый }\end{array}$ \\
\hline 3. & По временной зависимости & $\begin{array}{c}\text { Ретроспективный, предупредительный или } \\
\text { опережающฺй, текущฺий }\end{array}$ \\
\hline 4. & По частоте процедур & Разовый, периодический, систематический \\
\hline 5. & По охвату объекта наблюдения & Локальный, выбороччный, сплочной \\
\hline 6. & По организационным формам & Индивидуальнылй, групповой, фронтальный \\
\hline 7. & $\begin{array}{c}\text { По формам объект-субъект } \\
\text { отношений }\end{array}$ & $\begin{array}{c}\text { Внешний или соииальныій, взаимоконтроль, } \\
\text { самоанализ }\end{array}$ \\
\hline 8. & $\begin{array}{l}\text { По используемому } \\
\text { инструментарию }\end{array}$ & $\begin{array}{c}\text { Стандартизированный, нестандартизиро- } \\
\text { ванный, матричный и др. }\end{array}$ \\
\hline
\end{tabular}

Остановимся кратко на некоторых уровнях и видах мониторинга, определяя их функции:

- индивидуальный - учитель осуществляет отслеживание различных сторон учебного процесса: уровень развития учащихся, состояние успеваемости, качество сформированных ключевых компетенций;

- внутришкольный - мониторинг уровня сформированности обязательных результатов обучения в виде административных контрольных работ;

- стартовый (входной) - степень устойчивости знаний учащихся (выясняются причины потери знаний за летний период, намечаются меры по устранению пробелов);

- промежуточныій (тематический, четвертной, полугодовой) - отслеживается динамика уровней сформированности компетенций у учащихся, корректируется деятельность учителя и учеников;

- итоговый (годовой) - определяется уровень сформированности компетенций при переходе в следующий класс, прогнозируется результативность дальнейшего обучения, выявляются недостатки в работе, планируются технологии прослеживания результатов учебно-воспитательной деятельности на сле- 
дующий учебный год по предметам и классам, по которым получены неудовлетворительные результаты мониторинга.

Формализованный мониторинг позволяет определить критерии объектов образовательного процесса, основные направления, блок показателей качества образовательного процесса и ее результатов. Рассмотрим эти блоки:

Объекты внутришкольного мониторинга качества образования:

- индивидуальные образовательные достижения обучающихся;

- качество организации образовательного процесса;

- профессиональная компетенция педагогов, их деятельность по обеспечению требуемого качества результатов образования;

- комфортность обучения;

- доступность образования;

- сохранение контингента обучающихся;

- система дополнительных образовательных услуг;

- состояние здоровья обучающихся;

- воспитательная работа;

- материально-техническое обеспечение образовательного процесса.

Основные направления мониторинга:

Блок показателей качества потенцииала достижения цฺелей:

- основные образовательные программы;

- дополнительные образовательные программы;

- объекты общей и социальной инфраструктуры;

- материально-технические условия реализации программы (критерии см. в «Примерная основная образовательная программа образовательного учреждения. Основная школа»;

- информационно-методические условия реализации программы (см. там же);

- кадры;

- обучающиеся.

Блок показателей качества образовательного процесса:

- реализация учебных планов и рабочих программ; 
- используемые образовательные технологии;

- соблюдение законодательства РФ в области образования;

- наличие площадок для свободного самовыражения обучающихся.

- удовлетворённость участников образовательного процесса.

Блок показателей качества образовательных результатов:

- предметные знания и умения обучающихся;

- сформированность способов деятельности (компетентности);

- социальный опыт самореализации и самовыражения;

- здоровье обучающихся.

Блок показателей эффективности реализации образовательной организацุии «Программы воспитания и сощуиализаџчии обучающуихся»:

- особенности развития личностной, социальной, экологической, трудовой, и здоровье-сберегающей культуры обучающихся;

- социально-педагогическая среда, общая психологическая атмосфера и нравственный уклад школьной жизни в образовательном учреждении;

- особенности детско-родительских отношений и степень включенности родителей (законных представителей) в образовательный и воспитательный процессы.

Далее необходимо остановиться на мониторинге результатов воспитательной деятельности образовательной организации. Известно, что воспитательный процесс, согласно требованиям ФГОС, в образовательной организации осуществляется на основе реализации программы «Воспитания и социализации обучающихся». Названная программа предусматривает разные уровни сформированности обучающихся. Выявление и формализация уровней воспитанности обучающихся на современном этапе - одна из самых актуальных проблем в педагогике. Это связано с тем, что объект воспитания - это уникальная личность, системное образование, которая вступает в отношения с такими же системными образованиями (педагоги и обучающиеся). В процессе этих отношений личность проходит несколько стадий социализации, показателями этих процессов и будут уровни воспитанности. Выявить уровни воспитанности у современных 
обучающихся с объективными показателями достаточно сложно. Тем не менее, с точки зрения педагогической науки считается, что одним из эффективных методик выявления уровней воспитанности обучающихся является диагностика процесса воспитания учащихся. На основе полученных данных педагогической диагностики возможно корректирование и совершенствование воспитательной деятельности в образовательной организации.

Мониторинг воспитательной деятельности в образовательной организации должен определяться общепринятой методологией и требованиями ФГОС. Для достоверного отражения состояния воспитательного процесса важно правильно применять формализованную систему отражения результатов мониторинга. С этой целью необходимо применять методологический инструментарий мониторинга воспитания и социализации обучающихся.

В методологический инструментарий мониторинга воспитания и социализации обучающихся входит использование следующих методов: тестирование; опрос (анкетирование, интервью, беседа); психолого-педагогическое наблюдение; психолого-педагогический эксперимент; методы сбора информации: опрос, отчёт классного руководителя, анкетирование, тестирование и т. д.

Критерии эффективности реализации образовательной организацией воспитательной и развивающей программы принято определять на основе выявления динамики основных показателей воспитания и социализации обучающихся:

1) динамика развития личностной, социальной, экологической, трудовой и здоровье-сберегающей культуры обучающихся;

2) динамика (характер изменения) социальной, психолого-педагогической и нравственной атмосферы в образовательном учреждении;

3) динамика детско-родительских отношений и степени включенности родителей (законных представителей) в образовательный и воспитательный процессы.

В свою очередь, показателями эффективности реализации образовательным учреждением «Программы воспитания и социализации обучающихся» составленной на основе требований ФГОС, выступают: 
1) особенности развития личностной, социальной, экологической, трудовой, и здоровье-сберегающей культуры обучающихся;

2) социально-педагогическая среда, общая психологическая атмосфера и нравственный уклад школьной жизни в образовательном учреждении;

3) особенности детско-родительских отношений и степень включенности родителей (законных представителей) в образовательный и воспитательный процесс.

Итак, на основе вышеизложенного необходимо отметить, что цель педагогического сопровождения формализованной системы мониторинга реализации требований ФГОС заключается в обеспечении: эффективного информационного отражения состояния образования в конкретном субъекте образования (см. ст. 28 и 29 Федерального закона «Об образовании в РФ»); анализа результатов его деятельности на основе полученных количественных и качественных показателей; разработки прогнозирования развития образовательной системы образовательного учреждения. (Результаты мониторинга необходимо оформить в формализованном виде в виде таблицы.)

\section{Список литературы}

1. Данилюк А.Я. Концепция духовно-нравственного развития и воспитания личности гражданина России / А.Я. Данилюк, А.М. Кондаков, В.А. Тишков. М.: Просвещение, 2009. - 23 с.

2. Письмо МО и Н РФ от 15. 10 2003г. «О методических рекомендациях по процедуре аттестационной и аккредитационной оценке воспитательной деятельности ОУ»;

3. Приказ Министерства образования и науки РФ №986 от 04 октября 2010 года «Об утверждении федеральных требований к образовательным учреждениям в части минимальной оснащённости учебного процесса и оборудования учебных кабинетов»; 
4. Руссков С.П. Социально-педагогические технологии в условиях модернизации образования // Модернизация современного образования: проблемы и перспективы - Умань: ВПЦ «Визави», 2018 - С. 174-179.

5. Федеральный государственный образовательный стандарт основного общего образования. - М.: Просвещение, 2011. - 48 с.

6. Федеральный закон «Об образовании в Российской Федерации» от 29 Декабря 2012 г. №273-Ф3 «Об образовании Российской Федерации». [Электронный ресурс]. - режим доступа: http://www.consultant.ru/document/cons_doc_LAW_140174/ (дата обращения: 29.05.2019).

7. Фундаментальное ядро содержания общего образования / под ред. В.В. Козлова, А.М. Кондакова. - М.: Просвещение, 2011. - 79 с.

\section{References}

1. Daniliuk, A. Ia., Kondakov, A. M., \& Tishkov, V. A. (2009). Kontseptsiia dukhovno-nravstvennogo razvitiia i vospitaniia lichnosti grazhdanina Rossii., 23. M.: Prosveshchenie.

2. Pis'mo MO i N RF ot 15. 10 2003g. "O metodicheskikh rekomendatsiiakh po protsedure attestatsionnoi i akkreditatsionnoi otsenke vospitatel'noi deiatel'nosti OU";

3. Prikaz Ministerstva obrazovaniia i nauki RF 986 ot 04 oktiabria 2010 goda "Ob utverzhdenii federal'nykh trebovanii k obrazovatel'nym uchrezhdeniiam v chasti minimal'noi osnashchionnosti uchebnogo protsessa i oborudovaniia uchebnykh kabinetov";.

4. Russkov, S. P. (2018). Sotsial'no-pedagogicheskie tekhnologii v usloviiakh modernizatsii obrazovaniia. Modernizatsiia sovremennogo obrazovaniia, 174-179. Uman': VPTs "Vizavi".

5. (2011). Federal'nyi gosudarstvennyi obrazovatel'nyi standart osnovnogo obshchego obrazovaniia., 48. M.: Prosveshchenie. 
6. Federal'nyi zakon "Ob obrazovanii v Rossiiskoi Federatsii" ot 29 Dekabria 2012 g. 273-FZ "Ob obrazovanii Rossiiskoi Federatsii". Retrieved from http://www.consultant.ru/document/cons_-doc_LAW_140174/

7. Kozlova, V. V., \& Kondakova, A. M. (2011). Fundamental'noe iadro soderzhaniia obshchego obrazovaniia., 79. M.: Prosveshchenie.

Руссков Станислав Пименович - канд. пед. наук, доцент БУ ЧР ДПО «Чувашский республиканский институт образования» Минобразования Чувашии, Россия, Чебоксары.

Russkov Stanislav Pimenovich - candidate of pedagogical sciences. assistant professor at the BE of FVE «Chuvash Republican Institute of Education» of the Ministry of Education of Chuvashia, Russia, Cheboksary. 